\title{
PROGRAMA DINHEIRO DIRETO NA ESCOLA: PRÁTICAS GESTORAS DE ESCOLAS ESTADUAIS DA REGIÃO METROPOLITANA NORTE DE RECIFE/PE
}

http://dx.doi.org/10.5902/2318133866340

\author{
Grécia Gracielle da Silva Bezerra ${ }^{1}$ \\ Laêda Bezerra Machado²
}

\begin{abstract}
Resumo
Neste texto apresenta-se o como funciona a gestão e o controle social do Programa Dinheiro Direto na Escola - PDDE - em escolas estaduais da Região Metropolitana Norte de Recife/PE, evidenciando as formas de participação da comunidade escolar e o papel das equipes gestoras no fomento à autogestão democrática. Trata-se de um estudo descritivo, realizado por meio de entrevista semiestruturada com sete profissionais da gestão escolar vinculadas a escolas com unidades executoras próprias do PDDE. Os dados foram organizados com o apoio da análise de conteúdo. Os resultados indicaram que a gestão e controle social do PDDE estão concentrados na gestão escolar e que isto ocorre em razão de condicionantes materiais e institucionais comuns nas escolas públicas. Têm sido diminutas as práticas de participação e controle social nos destinos do Programa.
\end{abstract}

Palavras-chave: gestão escolar; PDDE; participação; controle social.

\section{THE MONEY DIRECT AT SCHOOL PROGRAM: MANAGING PRACTICES OF STATE SCHOOLS IN THE NORTHERN RECIFE/PE METROPOLITAN REGION}

\begin{abstract}
This article identifies how the management and social control of the Programa Dinheiro Direto na Escola - PDDE - takes place in state schools in the Northern Metropolitan Region of Recife/PE, highlighting the forms of participation of the school community and the role of management teams in promoting self-management democratic. This is a descriptive study, carried out through semistructured interviews with seven school management professionals linked to schools with PDDE's own executing units. Data were organized with the support of content analysis. The results indicated that the management and social control of the PDDE are concentrated in school management. This is due to material and institutional constraints common in public schools. Participation and social control practices in the Program's destinations have been reduced.

Keywords: school management; PDDE; participation; social control.
\end{abstract}

\footnotetext{
1 Universidade Federal de Pernambuco, Brasil. E-mail: bezerraaicerg@gmail.com.

2 Universidade Federal de Pernambuco, Brasil. E-mail: laeda01@gmail.com. 


\section{Introdução}

desenvolvimento de programas educacionais advindos da esfera pública explicita as intencionalidades do Estado acerca dos rumos da educação num determinado período. As alterações nas formas de organização das responsabilidades com a educação repercutem na cultura organizacional dos estabelecimentos públicos de ensino, suscitando novos desafios, sobretudo, para a gestão escolar.

Este artigo toma como objeto de estudo a prática de equipes gestoras no que se refere à participação da comunidade escolar nos órgãos colegiados vinculados ao Programa Dinheiro Direto na Escola - PDDE - na Região Metropolitana Norte de Recife/PE.

Por equipe gestora entende-se um corpo funcional composto por profissionais da gestão que tem como propósito liderar e orientar ações, a fim de garantir o bom funcionamento da unidade escolar a fim de que ela cumpra a sua função social. Salientamos que o conceito de gestão escolar ora explorado baseia-se no princípio de gestão democrática do ensino público.

Por comunidade escolar compreendemos um conjunto de pessoas que vivenciam e estabelecem diferentes ligações com a realidade da escola: são alunos, pais, responsáveis, professores, equipe gestora, demais funcionários e indivíduos do entorno escolar.

O PPDE surgiu como Programa de Manutenção e Desenvolvimento do Ensino Fundamental - PMDE - e, desde sua instituição em 1995, fundamenta-se no princípio de descentralização do Estado para com a educação. O Programa prevê estímulo à criação das unidades executoras próprias, circunscritas à esfera pública não estatal, desburocratização do repasse e da gestão dos recursos provenientes do salárioeducação. Constitui-se como um recurso de fomento à infraestrutura física e pedagógica dos estabelecimentos de ensino.

Tendo em vista a consolidação do PDDE na educação pública brasileira e, principalmente, os princípios os quais o fundamentam - autonomia e participação - teve-se como objetivo identificar, junto às equipes gestoras de escolas estaduais da Região Metropolitana Norte de Recife/PE, como tem acontece o processo de gestão do Programa, explicitando as formas de participação e o envolvimento da comunidade escolar na gestão do referido Programa.

\section{O Programa Dinheiro Direto na Escola - PDDE: origem e trajetória no contexto da educação pública brasileira}

O Programa de Manutenção e Desenvolvimento do Ensino Fundamental - PMDE foi criado pela resolução n. 12, de maio de 1995, e hoje intitula-se Programa Dinheiro Direto na Escola - PDDE -, instituído por meio da medida provisória n. 1.784, de 14 de dezembro de 1998.

O Programa foi criado com a proposição inicial de fornecer assistência financeira, em caráter suplementar, às escolas públicas do ensino fundamental das redes estadual, do Distrito Federal e dos municípios, por repasses de recursos financeiros coordenados 
pelo Fundo Nacional de Desenvolvimento da Educacional - FNDE. Tem como propósito garantir um padrão mínimo de qualidade do ensino com a melhoria física e pedagógica das instituições e, ainda, equalizar as desigualdades regionais educacionais pelo princípio redistributivo.

Os recursos destinados ao PDDE têm como fonte o salário-educação, contribuição social advinda de pagamentos feitos por empresas ao Instituto Nacional do Seguro Social (Brasil, 1988). No artigo 20, a resolução n. 3, de 21 de janeiro de 1999, do FNDE, estabelece que os recursos do Programa devem ser destinados à cobertura de despesas que venham a contribuir para o melhor funcionamento das instituições, tais como: I aquisição de material permanente; II - manutenção, conservação e pequenos reparos na unidade escolar; III - aquisição de material de consumo necessário ao funcionamento da escola; IV - capacitação e aperfeiçoamento de profissionais da educação; V - avaliação da aprendizagem; VI - implementação de projeto pedagógico; e VII - desenvolvimento de atividades educacionais (Brasil, 1999). Pela resolução delimita-se que as transferências são feitas com base nos dados extraídos do censo escolar do ano anterior, realizado pelo Ministério da Educação para informar o número de alunos matriculados em cada instituição, posto que os valores repassados são calculados a partir de valores fixos somados ao valor per capita-aluno.

Atualmente, além de subsidiar a Universidade Aberta do Brasil e as escolas privadas de educação básica que oferecem educação especial, o PDDE focaliza suas ações na educação básica pública. É constituído, desde 2007, em PDDE Integral, PDDE Estrutura e PDDE Qualidade. Esses programas abarcam ações agregadas que possuem finalidades específicas de fomento à infraestrutura das escolas e o desenvolvimento pedagógico, com vistas a garantir a qualidade da educação.

O PDDE Integral tem como foco a ampliação e a melhoria das atividades pedagógicas. É sistematizado a partir de ações complementares como, por exemplo, a ação agregada Mais Educação que, destinada ao público do ensino fundamental e, oferece atividades de reforço nas áreas Língua Portuguesa e Matemática, além de e outras atividades extracurriculares demandadas pela escola.

O PDDE Estrutura beneficia especificamente as áreas relativas à infraestrutura das unidades, financia ações como o Escola Acessível, Água na Escola e Escola do Campo, que vêm a suprir o desenvolvimento da capacidade física das instituições de ensino destinadas a públicos específicos.

Por fim o PDDE Qualidade favorece ações referentes ao acesso à internet, ao aprimoramento da qualidade do ensino médio, desenvolvimento de projetos culturais e esportivos, dentre outros. Destacamos ações como Educação Conectada, Novo Ensino Médio, Atleta na Escola e Mais Cultura nas Escolas.

De acordo com o relatório de gestão de 2019 do Fundo Nacional de Desenvolvimento da Educação (Brasil, 2019), em relação à execução do PDDE ocorreu um repasse de mais de 796 milhões de reais, contemplando cerca de 115 mil instituições educacionais. Ainda, 270 milhões foram repassados para a concretização das ações agregadas vinculadas ao Programa, favorecendo as escolas selecionadas. 
Essas informações confirmam o papel do PDDE como um importante aparato do financiamento educacional no país, além de um mecanismo com potencial para fortalecer, sobretudo, a capacidade autogerenciável e a democracia nas escolas públicas, com consequente melhoria na qualidade das práticas pedagógicas.

Desde sua instituição, o PDDE pressupõe a garantia da autonomia escolar e capacidade de aplicar os recursos, de acordo com as suas realidades. Assim, a fim de garantir "maior flexibilidade na gestão dos recursos repassados e ampliar a participação da comunidade escolar nessa mesma gestão" (Adrião; Peroni, 2007, p.5), o Programa estabelece como um dos critérios para a consolidação dos repasses a criação de unidades executoras próprias. Como preconiza o art. 6ํำ da resolução n. 10 , de 18 de abril de 2013 (Brasil, 2013), serão beneficiadas pelo Programa as escolas públicas que possuírem mais de 50 alunos matriculados na educação básica que, deverão, em caráter obrigatório, criar suas unidades executoras próprias. Em conformidade, ainda, com o inciso segundo do artigo $5^{\circ}$ desse dispositivo legal, a unidades executoras próprias é compreendida como uma sociedade privada, que não possui fins lucrativos e tem a finalidade de representar os interesses das escolas públicas.

Assim, composta por intergrantes da comunidade escolar, a unidades executoras próprias assume denominações diversas, como conselho escolar, associação de pais e mestres, círculo de pais e mestres, caixa escolar, colegiado escolar, com o objetivo em comum de assumir a responsabilidade "pela formalização dos procedimentos necessários ao recebimento dos repasses do programa, destinados às referidas escolas [...], bem como pela execução e prestação de contas desses recursos" (Brasil, 2013).

Dessa maneira, as unidades executoras próprias devem garantir o controle social das ações previstas para o PDDE. O Programa prevê movimentos deliberativos ajustados à realidade de cada instituição e transparência no emprego do dinheiro público:

exercer plenamente autonomia de gestão do PDDE, assegurando à comunidade escolar participação sistemática e efetiva nas decisões colegiadas, desde a seleção das necessidades educacionais prioritárias a serem satisfeitas até o acompanhamento do resultado do emprego dos recursos do programa. (Brasil, 2013)

Nessa perspectiva, a viabilização do PDDE implica na consolidação de uma organização escolar fundamentada na democratização dos espaços de definição, deliberação e fiscalização acerca dos subsídios escolares. Compreendendo que o desenrolar das ações educativas públicas interessa a todos aqueles que possuem vinculação direta ou indireta com seus processos, a gestão democrática é o principio norteador para a efetivação e descentralização do Programa.

Segundo Gadotti (1997), para que a escola garantir um atendimento de qualidade, é imprescindível que a ela seja delegada a incumbência de atuar nas áreas pedagógica, administrativa e organizacional e, ainda, financeira. A instituição deve ser capaz de traçar seus rumos, que vão desde as formas de ensino, implementação de projetos até a definição de suas despesas. Abranches (2003) enfatiza que as decisões locais oriundas de uma coletividade explicitam a autonomia necessária ao processo exitoso de descentralização. Para ela, participação e descentralização são conceitos que se interrelacionam e um favorece a materialização do outro. 
O PDDE, ao instituir espaços representativos propícios para o encaminhamento das reais necessidades da unidade escolar, desencadeia a necessidade de planejamento, o acompanhamento, a avaliação e fiscalização. Assim, não se pode pensar numa gestão democrática dos recursos, sem antes estabelecer o envolvimento e a participação dos membros da comunidade educativa. De acordo com Paro (2017),

por mais colegiada que seja a administração da unidade escolar, se ela não inclui a comunidade, corre o risco de constituir apenas mais um arranjo entre os funcionários do Estado, para atender a interesses que, por isso mesmo, dificilmente coincidirão com os da população usuária. (p. 23)

Igualmente, ele elucida que a participação está relacionada ao poder e ao rompimento dos autoritarismos institucionais. Assim, a participação, sobretudo nas tomadas de decisões, é vista como a partilha do poder e, por isso mesmo, a instituição escolar tende a criar barreiras que afastam cada vez mais a comunidade de suas ações. Assim sendo, são estabelecidos condicionantes "materiais, institucionais, político-sociais e ideológicos" (Paro, 2017, p. 57) quanto à participação. Portanto, não basta apenas estimular os sujeitos da comunidade escolar por meio de discursos democráticos, mas criar condições materiais e imateriais para que esses indivíduos participem, tenham consciência do projeto político-pedagógico ao qual todos devem seguir e enxerguem na implementação das ações o sentido de ser da escola.

Uma vez que "o controle social é um componente da gestão democrática, designa várias ações e mecanismos por meio dos quais a sociedade civil sabe, conhece e interfere na elaboração e gestão das políticas públicas" (Guimarães; Coutinho, 2010, p. 164), pode-se identificar que a gestão financeira inerente ao PDDE é um fator que intensifica a indispensabilidade de um acompanhamento social consciente e, acima de tudo, transparente.

Nesse viés, verificamos que a concentração de tarefas administrativas e burocráticas alocada na equipe gestora escolar, sobretudo na figura do gestor, pode resultar em concentração de poder e de detenção da informação, pois "como a tomada de decisão em si é inócua e só se completa na ação, o poder é exercido não apenas por quem toma decisão, mas também por aqueles a quem compete pôr em prática a decisão tomada" (Luck, 2009, p. 122). Assim, a gestão escolar possui um importante papel no sentido de adotar práticas compartilhadas de organização sobre as definições, ações e acompanhamento do enredo escolar e da consolidação das políticas públicas educacionais.

Neste contexto, procuramos identificar a produção científica acerca desse Programa em plataformas de periódicos voltadas para os campos científicos da política educacional e gestão educacional. Tomando como base para as filtragens os termos "PDDE", "gestão escolar" e "controle social", obtivemos melhores resultados a partir da busca com a sigla "PDDE", apenas. Foram encontrados cinco artigos que dialogam de alguma forma com que abordamos neste texto. 
No estudo intitulado Política de financiamento da educação e participação da comunidade na gestão da escola, Santos (2006) destaca as repercussões do PDDE em três unidades escolares do município de Camaragibe/PE e, ainda, identifica em que medida as diretrizes formuladas pelo poder central estavam ou não sendo redirecionadas localmente.

O trabalho de Peroni (2006) Financiamento da escola à luz do novo papel do Estado: o caso do Rio Grande do Sul toma como objeto o PDDE e suas implicações para a organização e o funcionamento da escola pública e destaca a constituição de unidades executoras como entidades de direito privado nos estados do Rio Grande do Sul, São Paulo, Piauí, Pará e Mato Grosso do Sul.

O artigo Avanços e desafios no processo de implementação do Programa Nacional de Alimentação Escolar (PNAE) e o Programa Dinheiro Direto na Escola (PDDE), de Lima et al (2016), trata sobre o funcionamento e a gestão do PDDE e do PNAE Na Rede Estadual De Ensino do Município de Irati/PR enfatizando avanços e desafios no processo de implementação dos mencionados programas.

Denominado Recursos financeiros na escola: visão de diretores em cinco municípios do Ceará o texto de Sousa et al, (2020) analisa as percepções dos gestores escolares quanto às questões relacionadas aos recursos financeiros que chegam às escolas, inclusive os do PDDE, enfoca aspectos relativos ao gerenciamento, a participação escolar, as formas de divulgação da prestação de contas e, também, os avanços e desafios quanto à gestão financeira.

Meneses e Brasil (2018), em Gestão Democrática na escola: a participação no contexto da prática de um programa de educação em tempo integral, aborda a participação da comunidade escolar nos processos que envolvem a implementação do PME numa escola da rede municipal de Belém/PA.

Com o levantamento realizado verificamos que, na atualidade, as pesquisas que exploram especificamente o PDDE e sua materialização no contexto da gestão democrática ainda são escassas. O material encontrado apresenta semelhanças com 0 artigo aqui apresentado, no entanto a ênfase no controle social do Programa e sua gestão coletiva poderá oferecer maiores contribuições para o entendimento das desafios para efetivação dos princípios de gestão democrática e descentralização do financiamento da educação pública

\section{Metodologia}

O estudo foi desenvolvido em três escolas públicas da rede estadual de ensino de Pernambuco, situadas na Região Metropolitana Norte de Recife/PE. Os critérios para a escolha das escolas levaram em consideração o aspecto geográfico, de modo a contemplar três municípios diferentes da Região Metropolitana Norte de Recife/PE, como também o número de alunos matriculados nas instituições, posto que essa é uma variável que determina maior ou menor presença do PDDE nas escolas.

Para preservar a identidade das instituições, denominamos as escolas como escola 1, 2 e 3. A Escola 1 é localizada no município de Abreu e Lima/PE, oferece os anos finais do ensino fundamental, ensino médio e EJA e possui 501 alunos matriculados. A escola 2 está situada no município de Paulista/PE, oferece o ensino médio e EJA e conta com 395 alunos matriculados. A escola 3 localiza-se no município de Olinda/PE, oferece os anos 
finais do ensino fundamental, ensino Médio e EJA e possui 602 alunos matriculados. Todas as instituições dispõem de unidades executoras próprias ativas e possuem em sua composição ao menos um representante de cada segmento da comunidade escolar, sendo presididas pelo gestor. Participaram da pesquisa sete membros das equipes gestoras dessas escolas, sendo três da escola 1, dois da escola 2 e dois da escola 3 , que atuam nas unidades executoras próprias do PDDE.

As participantes são todas mulheres com idades entre 43 e 60 anos e têm de 5 a 11 anos de atuação na gestão das escolas investigadas. Todas são formadas em cursos de licenciatura e a maioria possui algum tipo de formação voltada para a área das Ciências Humanas. Todas as gestoras entrevistadas são presidentes das unidades executoras próprias; as gestoras adjuntas são vice-presidente e tesoureira e a secretária e a analista são conselheiras deliberativas. Como procedimento de coleta de dados utilizamos a entrevista semiestruturada.

Tendo em vista o quadro de pandemia e suas implicações, a coleta de dados aconteceu de maneira virtual, por meio da plataforma Google Meet, que viabiliza a realização de chamadas de vídeo. Apenas um bloco de entrevistas foi feito de maneira presencial. Realizamos as entrevistas considerando a disponibilidade das participantes, ou seja, nos três turnos e em variados horários, conforme permitiram suas agendas. Convém dizer que o formato propiciado pelo Google Meet possibilitou que esse contato fosse bastante aproximado do convencional, pois foi possível ouvir e ver as entrevistadas em tempo real, com o suporte, ainda, da ferramenta de gravação de vídeo, que auxiliou na transcrição das manifestações. Todas as participantes dispunham de boa conexão de internet e demonstraram comodidade e espontaneidade no decorrer das entrevistas. Para análise dos dados coletados utilizamos a técnica de análise de conteúdo (Bardin, 2016).

\section{Apresentação e discussão dos resultados}

Tomando por base o valor da parceria da escola com a comunidade para a garantia dos processos democráticos e, principalmente o papel das unidades executoras próprias do PDDE, buscamos entender as concepções das equipes gestoras acerca do conceito de comunidade escolar e as formas de participação existentes nas unidades escolares.

No que diz respeito às percepções das participantes sobre o conceito de comunidade escolar, é possível identificar que todas elas fazem referência a um grupo de sujeitos que está inserido dentro da escola e participa do seu cotidiano. Foram citados na maior parte dos depoimentos os professores, os alunos, os responsáveis, os membros da gestão e os demais funcionários. Cinco entrevistadas, associam o conceito às pessoas das comunidades locais nas quais as escolas estão inseridas, como evidencia a secretária da escola 1:

Comunidade escolar são todos os envolvidos na escola como um todo, então, isso envolve tanto as pessoas de dentro da escola, desde o porteiro, a merendeira, os professores, os estudantes, mas também a comunidade em si, na qual a escola está inserida. (Secretária Escola 1) 
Quando questionadas a respeito das vantagens do processo de integração e participação da comunidade escolar nos órgãos colegiados do PDDE, seis foram enfáticas ao expressarem que enxergam vantagens nesse sentido, pois essa dinâmica favorece a ação coletiva em relação às decisões, fazendo com que as reais necessidades das unidades escolares sejam atendidas:

Com certeza. É através desse colegiado que a gente sabe direcionar de maneira eficaz, pontual e satisfatória as necessidades da escola [...] como os grupos são plurais, então, a visão também fica plural. [...] a gente utiliza de forma mais assertiva. (Gestora adjunta escola 2)

Os depoimentos das participantes estão em consonância com algumas finalidades elencadas pelo FNDE no que diz respeito à concretização do PDDE a nível local, como exposto no Manual de orientação para constituição de unidade executora própria (2014), quando afirma que tal entidade pode ser instituída por pessoas da escola ou da comunidade local, além de estabelecer como passos fundamentais para sua efetivação a motivação e integração dos vários sujeitos, para que compreendam os sentidos que permeiam as unidades executoras próprias e participem das suas definições. Na mesma direção, Botler e Marques (2013, p. 182) reforçam a importância da corresponsabilização para o sucesso da descentralização das políticas educacionais e dão ênfase à aproximação da comunidade escolar na definição sobre a escola pública, com fins a novos processos culturais.

Identificamos que apenas uma entrevistada demonstrou dissonância no que se refere a esses aspectos, apontando desvantagens associadas à discussão coletiva e ampla dentro dos movimentos decisórios, em razão das discordâncias decorrentes das deliberações, mostrando uma preferência por uma limitação no número de pessoas envolvidas nesses momentos:

Vantagem eu não vejo, não. É vantajoso quando você tem somente um representante de cada setor, não de uma forma mais ampla, porque eles não vão entender esse funcionamento e vão querer que a escola compre coisas que não podem, aí gera até discussão. (Gestora escola 1)

A opinião da gestora da escola diverge de Lück (2017) ao reiterar que um dos caminhos possíveis para o rompimento da marginalização dos sujeitos - que não compõem a gestão escolar - é justamente a predisposição das lideranças para o diálogo, além do esforço e atenção demandados em relação aos conflitos postos, de modo a compreendê-los e superá-los, com fins a construir um compartilhamento real do poder dentro da escola.

Nesse segmento, apesar dos depoimentos da maioria das participantes convergirem com fundamentos teóricos democráticos, quando falam sobre as vantagens da participação de todos os segmentos da comunidade escolar nos órgãos colegiados do PDDE, a conjuntura apresentada pela maioria retrata uma série de elementos que se aproxima mais de um quadro de dispersão e desintegração do que de participação dessa comunidade. 
Portanto, quando procuramos aprofundar de que formas a comunidade escolar vem participando da gestão do PDDE, sobretudo no que se refere aos momentos de definição, acompanhamento e fiscalização do Programa, cinco das sete entrevistadas revelaram indefinição, oscilação de ideias ou facetas destoantes do previsto em relação à autogestão do Programa:

"Até agora, na minha gestão, não. [...] É uma coisa que a gente vai vivendo os problemas da escola e não dá para ver essa parte. [...] as merendeiras, os SG's, eles participam, sim porque quando elas dizem as necessidades, eu considero que elas estão participando dessa decisão de comprar determinados itens." (Gestora escola 1)

"Em relação à fiscalização, se eles pedirem, tem o material à disposição, mas não é uma coisa que a gente tenha tempo para reunir para mostrar, devido à demanda." (Gestora adjunta escola 1)

"A gente tem já construído aqui no pensamento, o que a gente precisa [...] a gente conversa com essas pessoas já direcionando mais ou menos aquilo que a gente vê que há necessidade de atender na escola. Eu também gosto de sentar e conversar com os professores [...]. A gente conversou com professor e a gente entende que vai atender ao que? $\grave{A}$ comunidade escolar, aos alunos." (Gestora escola 3)

"Nunca presenciei, eu não sei te dar essa resposta. Eu não posso dizer nem que participam, nem que não participam, porque não vi ações nesse sentido." (Analista em gestão escola 3)

Para além das negativas, nos depoimentos prevalece a concepção de participação restrita a definição necessidades escolares. Os depoimentos sugerem práticas distantes das tomadas de decisões como processos coletivos e deliberativos, embora exista abertura, por parte da gestão escolar, para escuta, conversas informais e individualizadas acerca das prioridades com alguns sujeitos dos segmentos escolares.

A esse respeito Lück (2017) problematiza o conceito de participação como presença. Conforme a autora, é comum que no contexto escolar os sujeitos associem a democracia à mera presença física dos indivíduos em situações obrigatórias, que derivam de eventualidades e necessidades próprias do caráter formal de determinados processos educativos e resultam em posturas passivas, reativas e apáticas por parte da ampla comunidade escolar, reforçando a desorientação e falta de intencionalidade coletiva na gestão da escola.

Ressaltamos que apenas duas gestoras, as da escola 2, deram indicativos de gestão do Programa que sugerem o compartilhamento e fiscalização das ações desenvolvidas através da unidade executora própria:

"Através dos conselhos deliberativos [...] das reuniões que nós fazemos. [...] a gente convoca, nem sempre essa convocação atinge os $100 \%$...aí, as propostas são feitas [...] todo mundo opina e, aí, a gente vai vendo a necessidade [...] é na situação da decisão e depois na situação do acompanhamento da execução, porque a gente precisou de um bebedouro, mas esse bebedouro nunca vai aparecer? Não pode! Então, após a realização da compra, é que essa devolutiva é dada ao conselho." (Gestora adjunta escola 2) 
Assim, mesmo dando indícios de dificuldades quanto à mobilização dos sujeitos no dia a dia escolar, os depoimentos dessas gestoras estão em articulação como o que é dito por Libâneo, Oliveira e Toschi (2017) sobre a participação da comunidade escolar, ao assinalarem que "a participação da comunidade possibilita à população o conhecimento $e$ a avaliação dos serviços oferecidos e a intervenção organizada na vida escolar" (p. 488).

Em vista disso, os dados revelam que as profissionais têm percepções acerca do conceito de comunidade escolar que incluem os vários sujeitos diretamente ou indiretamente envolvidos com o espaço escolar. No que diz respeito ao PDDE, como elencado pelas gestoras da escola 2, a comunidade escolar vem participando por meio de encontros deliberativos e fiscais viabilizados pelo colegiado. Identificamos também que, conforme os depoimentos, há certa marginalização da comunidade escolar e limites na autogestão democrática do PDDE.

Além de perceber como vem sendo construída a autogestão do PDDE nas escolas, a participação dos vários segmentos escolares nesse processo, buscamos identificar quais são os empecilhos e avanços que as equipes gestoras conseguem enxergar ao longo desse processo.

Todas as participantes mencionaram o fator tempo como uma das principais dificuldades apresentadas no cotidiano escolar. As participantes explicam que a falta de disponibilidade resulta em inúmeras tentativas de quórum mínimo para as reuniões e, muitas vezes, inviabiliza essas tomadas coletivas:

“Não tenho momentos de pausas na rotina 'pra' tratar com essas pessoas [...] Falta tempo [...] geralmente ficam mais afastados." (Gestora escola 1)

"Não vou dizer a você que é 100\% [...] se a gente tiver 10 pessoas, a gente consegue trazer 5, 6." (Gestora escola 2)

"A dificuldade é justamente de tempo, da gente conseguir ter esse momento de parar." (Gestora escola 3)

Cabe ressaltar, ainda, que cinco entrevistadas interligam essa falta de tempo ao excesso de atribuições concentrado na gestão escolar. Tal concentração se dá em razão das inúmeras necessidades impostas pelas relações interpessoais e a subsistência material e administrativa da escola. A esse respeito afirmam:

"Você não pode dar conta de tudo sozinha dessa forma... Porque se tem uma aluna com cólica, aí vem...se o aluno briga, no outro dia 'tá' o pai ou a mãe aqui...quando não é isso, chega algum menino aqui chorando por causa dos problemas em casa...tudo canaliza, sabe? Muita coisa mesmo, muitas demandas." (Gestora escola 1)

“Surgem muitas demandas 'pra' gente fazer [...] eu pego merenda, eu pego kit escolar que chegou, eu vou subir 'pra' falar com estudante, eu converso com professor...Além de apagar as pequenas "fogueiras" dos relacionamentos." (Gestora escola 3)

"A questão de pessoal [...] às vezes as questões de estrutura física do prédio...que terminam direcionando o tempo, a energia, o foco 'pra' muita coisa ao mesmo tempo e a gente fica ali tentando "apagar incêndio" e não 
consegue dar conta de tudo [...] e o PDDE, a UEX, é mais uma delas. Não se trata de dizer se é menos ou mais prioritário, eu acho que termina por ser uma área prejudicada, por conta [...] de uma questão estrutural, que vem de cima para baixo." (Analista em gestão escola 3)

Os trechos da rotina das participantes personificam o que Paro (2017) chama de condicionantes materiais da participação. Ele elucida que as condições objetivas que determinam a realização das ações e relações escolares, no contexto público, terminam por consumir a energia e o tempo do corpo escolar na gestão de problemas de inúmeras ordens, como a falta de infraestrutura e material adequados, além de questões com recursos humanos. Portanto, "às voltas com necessidades tão prementes, a escola em seu todo e as pessoas que aí atuam, em particular, acabam deixando para um plano secundário a preocupação com medidas tendentes a criar uma dinâmica interna de cooperação e participação" (p. 58). Sem desconsiderar esta problemática, o autor reforça que um dos caminhos possíveis para o rompimento desses obstáculos é justamente a instrumentalização de esforços coletivos em prol da superação e do pressionamento dos órgãos educacionais a esse respeito.

Os relatos de três das sete entrevistadas estão articulados ao que é dito por Paro (2017) como também complementam a lógica dos condicionantes institucionais da participação. Eles dizem respeito às dificuldades e responsabilidades para com as prestações de contas e de demandas estabelecidas pela Secretaria de Educação:

"A GRE manda vários questionários [...] Quanto mais a gente se afasta da gestão, mais difícil fica de entender. [...] Falta uma pessoa que cuide só da parte de prestação de contas, porque a prestação de contas já é uma gestão. [...] deveria haver dois gestores: um pedagógico e um financeiro." (Gestora escola 1)

"Eu lido com o financeiro mais diretamente, né...porque eu vou prestar contas disso, então eu que tenho que 'tá' à frente de compras [...] eu acho que a escola tinha que ter um gestor 'pra' o financeiro e um gestor 'pra' o pedagógico." (Gestora escola 3)

Acerca dos condicionantes institucionais da participação, Paro (2017) repete que a organização formal da escola fomenta a hierarquia e estabelece relações verticais, sobretudo em decorrência dos trâmites burocráticos delimitados pelas instâncias educacionais macroestruturais. Assim, os depoimentos das participantes trazem à tona a sobrecarga de trabalho do gestor escolar, principalmente, devido à ênfase nos aspectos burocráticos do PDDE. No que tange a essas questões, Adrião e Peroni (2007, p. 7) destacam que essa burocratização acaba por secundarizar a participação e controle social do recurso:

A correta prestação de contas junto ao Tribunal de Contas da União (TCU), tende a privilegiar a dimensão técnico-operacional e secundarizar a dimensão política própria dos processos coletivos de tomada de decisão com graus mais avançados de participação [...] concentrou ainda mais as opções de política escolar nas mãos dos diretores. (p. 7) 
Os depoimentos das profissionais acerca dos avanços presentes nas escolas no que diz respeito ao controle social pela ampla comunidade sugerem um quadro majoritário de inconsistência acerca do envolvimento de todos os atores escolares na democratização das informações.

Três entrevistadas informaram explicitamente que não enxergam avanços nesse sentido dentro da realidade escolar e outra usou a entrevista para sugerir aspectos do Programa a serem aprimorados, como podemos constatar em alguns fragmentos dos depoimentos:

"Eu acho que não avançou. Só avança quando eles têm dúvidas e eu explico." (Gestora Escola 1)

"Eu acho que o PDDE, ele precisa ser mais divulgado, precisa ser mais amplo e precisa ter mais recursos." (Secretária Escola 1)"

"Eu acho que eu não identifico, não. Eu não sinto esse avanço." (Analista em gestão escola 3)

De acordo com Roggero e Silva (2019), a efetiva participação da população nas questões de planejamento, execução, acompanhamento e o protagonismo nos aspectos financeiros, que pressupõem novas relações de poder na escola, ainda são entraves vinculados aos programas descentralizados, mesmo com a institucionalização dos conselhos colegiados.

Destacamos que a gestora da escola 1 também apresentou uma concepção restrita sobre o conceito de controle social, quando explica: "Eu acho que têm avanços, porque eu comparo quando eu era vice, eu não sabia de nada, e, se você perguntar à minha vice, ela sabe de tudo." Também, a gestora adjunta da escola 2 enfatizou a existência da transparência na materialização do Programa, justificando que "sempre, aqui na escola, a gente foi transparente nisso. Sempre. [...] Não. A gente trata diretamente nas reuniões." A gestora da escola 3, além de evidenciar dificuldade acerca da participação, aproximou o processo de controle social às pendências burocráticas supridas em sua gestão e ao contato que é estabelecido com os outros membros da gestão:

"O que eu entendo é que a gestão 'tá' melhorando, porque nós temos esse recurso que antes não tínhamos [...], mas não há, assim...eu acho que se a gente tivesse mais tempo 'pra' envolver mais pessoas, talvez houvesse um maior interesse nesse aspecto [...] sempre entro em contato com os educadores de apoio e com o pessoal que 'tá' comigo todo dia, né...o professor que é tesoureiro, o adjunto, o que é secretário...então, a gente sempre 'tá' conversando."

Do conjunto das entrevistadas apenas duas gestoras da escola 2 se referiram a avanços no controle das ações do PDDE. Justificam tais percepções por meio das atividades deliberativas e fiscalizadoras desenvolvidas pela escola:

A partir do momento que a gente se encontra, a gente 'tá' fazendo murais [...] tem a certeza de que os nossos estudantes, os nossos professores, os nossos terceirizados, os pais, né, os familiares...a comunidade em si...ela tem certeza do que 'tá' acontecendo na escola [...] é muito interessante essa coisa do colegiado por conta disso, porque não há sombra de 
dúvidas...se aquilo que 'tá' na escola foi porque a maioria decidiu [...] É como se eles dissessem assim: "a gente sabe o que tá acontecendo na escola." (Gestora adjunta escola 2 )

Sumariamente, a maior parte das equipes gestoras explicita as múltiplas barreiras que são encontradas no cotidiano da escola pública e expressam a relação desses condicionantes com o impedimento da autogestão democrática do PDDE, o que vem contribuindo para o panorama de poucos avanços concretizados pelas equipes gestoras em relação ao controle social da comunidade escolar, que é evidenciado de forma fidedigna pelas profissionais da Escola 2.

Para sabermos sobre a efetiva gestão do PDDE no âmbito de escolas públicas, indicamos com base nas entrevistas, as ações desenvolvidas pelas profissionais que expressam o controle social de sua gestão nas unidades escolares.

Quando questionadas sobre essas ações nas escolas, seis entrevistadas estabeleceram ligações com a realização de reuniões, todavia, atribuindo-Ihes sentidos e padrões diferentes:

"Por enquanto, não tem. As reuniões que a gente faz são mais pedagógicas e a gente fala com os pais a respeito de coisas da escola e do aluno." (Gestora escola 1)

"A gente geralmente faz reuniões...assim... não é uma reunião formal, a gente geralmente passa dois ou três meses 'pra' conseguir fazer uma." (Gestora escola 3)

Os trechos das entrevistas acima apresentados sugerem clareza em relação à necessidade de encontros coletivos, o que demonstra o vínculo dessa ação à demanda democrática do PDDE, no entanto, o modus operandis adotado evidencia negativas e contradições a respeito de um dos principais eixos de operacionalização do Programa nas escolas: as reuniões deliberativas e fiscais. Admitimos, portanto, que não se pode pensar numa adequada concretização do PDDE sem a efetiva unidade colegiada, posto que os repasses financeiros do Programa e ações agregadas ocorrem mais de uma vez a cada ano e pressupõem o compartilhamento, nas assembleias das unidades executoras próprias, no que tange ao planejamento, aquisição e prestação de contas dos gastos feitos por cada escola.

De acordo com Carvalho, Leão e Barbosa (2013), a atuação da gestão escolar no cenário público democrático está atrelada à ação-reflexão-ação e, sobretudo, ao reconhecimento os mecanismos de gestão colegiada como âmbitos de geração de novos caminhos para a escola, por favorecer debates, reuniões, elaborações e avaliações conjuntas, que alimentam a ética, responsabilidade e comprometimento mútuos, enquanto princípios essenciais da gestão democrática.

Nessa perspectiva, as gestoras da escola 2 apresentaram em seus depoimentos, indícios de tentativas de participação dos vários agentes escolares no colegiado do PDDE que, além de ampliarem as maneiras de ação utilizadas pela gestão escolar, estimulam o envolvimento dos sujeitos. 
As participantes sugerem a prática de reuniões sistemáticas, convocações intermitentes, readequação de horários e, ainda, a utilização do aplicativo WhatsApp como meios de integração entre os segmentos da escola. Os depoimentos demonstram a compreensão das profissionais a respeito do papel da gestão escolar como promotora de mobilizações e articulações, em prol da sustentação e dinamização das contribuições e esforços em sentido coletivo, a fim de melhorar a otimização dos investimentos em educação e a qualidade dos processos educativos.

Os depoimentos das gestoras estão de acordo com Santos (2006), quando trata sobre a relação da gestão democrática e a gestão da escola, à luz dos limites e condicionantes encontrados em sentidos epistemológicos, políticos e pedagógicos no contexto brasileiro, que valoriza a recriação de realidades complexas no contexto da prática, da superação de contradições, com os processos participativos.

Tomando como base tais elementos, percebemos que há no grupo pesquisado consensos a respeito das reuniões deliberativas e fiscais como principais meios de concretização da autogestão do PDDE. Eles favorecem o processo de gestão coletiva, no entanto, a maior parte das equipes gestoras ainda vive percalços para planejar tais processos, de modo a contemplar a democracia tal como preconiza o PDDE. Uma equipe gestora demonstra, ainda, a ampliação das ações democráticas a partir de tentativas de integração com a comunidade usuária, materializadas por convocações frequentes, reuniões, flexibilização de horários e uso da plataforma WhatsApp.

\section{Considerações finais}

Constatamos que a gestão do PDDE, na maioria das escolas investigadas, vem sendo construída com a preeminência de membros da gestão escolar, que se expressa em estacionamentos das dinâmicas do Programa. Por mais que se preconize o caráter democrático dessa política educacional sua vinculação a processos burocráticos e formais em detrimento do controle coletivo prevalece.

Identificamos forte interligação entre os impedimentos à realização do trabalho coletivo e os vários condicionantes comuns à realidade da escola pública, tais como: falta de pessoal, acúmulos de funções pelos profissionais, dificuldades de infraestrutura e de mediação de conflitos, centralização de poderes na pessoa do gestor ou equipe de gestão escolar. Tais obstáculos impedem o desenvolvimento de ações com vistas à corresponsabilização da gestão e controle social do PDDE nas escolas.

Paralelamente, foi possível verificar indícios de uma gestão do PDDE em conformidade com os princípios democráticos. Depreendemos nesse caso que a participação da comunidade escolar acontece por práticas colegiadas de definição, acompanhamento, deliberação e fiscalização das ações. Essas práticas são facilitadas não apenas pela crença na coletividade, mas por tentativas de integração dos segmentos escolares, que se materializam através de continuas convocações, readequação de horários e, ainda, criação de grupos no WhatsApp que facilitam a comunicação entre os diversos segmentos envolvidos.

Em face do exposto, trazemos à tona os modos como vem se concretizando as intencionalidades do Estado para com a educação por meio do PDDE. Indica os descaminhos e impasses que emergem das realidades escolares no sentido da promoção, corporificação e consubstancialização das práticas democráticas na escola.

\begin{tabular}{|l|l|l|l|l|l|}
\hline Regae: Rev. Gest. Aval. Educ. & Santa Maria & v. 10 & n. 19 & e66340, p. 1-17 & 2021 \\
\hline
\end{tabular}


Sem dúvida, as práticas democráticas caminham lado a lado com a elevação da qualidade dos processos de ensino e aprendizagem e favorecem o exercício da cidadania plena.

\section{Referências}

ABRANCHES, Monica. Colegiado escolar: espaço de participação da comunidade. São Paulo: Cortez, 2003.

ADRIÃO, Tereza; PERONI, Vera. Implicações do Programa Dinheiro Direto na Escola para a gestão da escola pública. Educ. Soc., Campinas, v. 28, n. 98, 2007, p. 253-267.

BARBOSA, Liliane Almeida; GONÇALVES, Liliane Jesus; Fernandes, Wellington Camargo. Gestão social participativa: um estudo em três escolas da educação básica no Estado de São Paulo. In: ROGGERO, Rosemary; SILVA, Adriana Zanini. Financiamento das escolas de educação básica na gestão democrática e participativa. São Paulo: BT Acadêmica, 2019, p. 233-251.

BARDIN, L. Análise de conteúdo. São Paulo: Edições 70, 2016.

BOTLER, Alice Mirian Happ; MARQUES, Luciana Rosa. Formação de gestores escolares na EAD e suas contribuições para a implementação da gestão democrática: uma análise da experiência de gestores em Pernambuco. In: MACHADO, Laêda Bezerra; CARVALHO, Liliane Maria. Teixeira Lima (orgs.). Gestão e Política Educacional: abordagens em diferentes contextos. Recife: UFPE, 2013, p. 175-197.

BRASIL. Constituição da República Federativa do Brasil. Brasília: Senado Federal, 1988.

BRASIL. Lei n. 9.394 de 20 de dezembro de 1996: estabelece as diretrizes e bases da educação nacional. Brasília: Casa Civil, 1996. Disponível em: <http://www.planalto.gov.br/ccivil_03/leis/19394.htm>. Acesso em: 10/10/2020.

BRASIL. Manual de orientação para constituição de unidade executora própria. Brasília: FNDE, 2014.

BRASIL. Manual de orientação para prevenção de falhas - unidades executoras próprias. Brasília: FNDE, 2018.

BRASIL. Relatório de gestão de 2019. Brasília: FNDE, 2019.

BRASIL. Resolução n. 3 de 21 de janeiro de 1999: dispõe sobre o PDDE e os critérios para repasse dos recursos. Brasília: FNDE, 1999.

CARVALHO, Liliane Maria Teixeira Lima; LEÃO, Maria Sandra Montenegro; BARBOSA, Marcia Regina. O papel do gestor e coordenador pedagógico na escola básica: o olhar de candidatos a um curso latu sensu do Daepe - UFPE. In: MACHADO, Laêda Bezerra; CARVALHO, Liliane Maria Teixeira Lima (orgs.). Gestão e política educacional: abordagens em diferentes contextos. Recife: UFPE, 2013, p. 11-31.

CRUZ, Rosana Evangelista da; GONÇALVES, Francisco Williams de A. Soares. LUZ, Liliene Xavier. O Programa Dinheiro Direto na Escola: democratização da gestão e reforma do Estado na educação. REUNIÃO DA ANPED, 29, 2006 anais ... Caxambu: Anped, 2006.

GADOTTI, Moacir. Da municipalização do ensino ao sistema único e descentralizado da educação básica. In: GADOTTI, Moacir; ROMÃO José E (org.). Autonomia da escola: princípios e propostas. São Paulo: Cortez, 1997, p. 1-7. 
MAIA, Maria Aparecida Santiago et al. Gestão financeira e a repercussão da empregabilidade dos recursos. In: ROGGERO, Rosemary; COSTA. Ana Araújo; PISANESCHI, Lucilene (orgs.). Financiamento da educação básica e a escola como agência multifuncional na sociedade neoliberal. São Paulo: BT Acadêmica, 2019, p.105145.

GUIMARÃES, Carlos Santa'nna; COUTINHO, Henrique Guimarães. Fundef: participação social e gestão democrática ou conselho governamental com participação tutelada? Revista Administração Pública e Gestão Social, Viçosa, v. 2, n. 2, 2010, p. 158-179.

HORA, Dinair Leal da. Gestão democrática na escola: artes e ofícios da participação coletiva. Papirus, 2016.

LIBÂNEO, José Carlos; OLIVEIRA, João Ferreira. de; TOSCHI, Mirza Seabra. Educação escolar: políticas, estrutura e organização. São Paulo: Cortez, 2017.

LIMA, Michelle Fernandes et al. Avanços e desafios no processo de implementação do programa nacional de alimentação escolar (PNAE) e o programa dinheiro direto na escola (PDDE). Revista Online de Política e Gestão Educacional, Araraquara, v. 20, n. 2, 2016, p. 301-321.

LUCK, Heloisa. Dimensões da gestão escolar e suas competências. Curitiba: Positivo, 2009.

LUCK, Heloisa. A gestão participativa na escola. Petrópolis: Vozes, 2017.

LUDKE, Menga; ANDRÉ, Marli Elisa Delmasio Afonso. Pesquisa em educação: abordagens qualitativas. São Paulo: EPU,1986.

MENEZES,Janaína Specht da Silva.; BRASIL, Rozineide Souza. Gestão democrática na escola: a participação no contexto da prática de um programa de educação em tempo integral. Revista Oline de Política e Gestão Educacional, Araraquara, v. 22, n. esp. 1, 2018, p. 137-158.

PARO, Vitor Henrique. Gestão democrática da escola pública. São Paulo: Cortez, 2017.

PERONI, Vera Marial Vidal. Financiamento da escola à luz do novo papel do Estado: o caso do Rio Grande do Sul. Revista Brasileira de Política e Administração da Educação, Porto Alegre, v. 22, n. 2, 2006, p. 331-344.

RODRIGUES, João Álvaro. Metodologia científica: completo e essencial para a vida universitária. São Paulo: Avercamp, 2006.

SANTOS, Inalda Maria dos. Política de financiamento da educação e participação da comunidade na gestão da escola. Revista Brasileira de Política e Administração da Educação, Porto Alegre, v. 22, n. 2, 2006, p. 315-329.

SILVA, Adriana Zanini; ROGGERO, Rosemary. A descentralização de recursos no financiamento da educação básica: financiamento das escolas de educação básica na gestão democrática e participativa. São Paulo: BT Acadêmica, 2019.

SOUSA, Esmeraldina Januário de; VIDAL, Eloisa Maia; VIEIRA, Sofia Lerche. Recursos financeiros na escola: visão de diretores em cinco municípios do Ceará. Revista online de Política e Gestão Educacional, Araraquara, v. 24, n. 1, 2020, p. 132-153.

SOUZA, Angelo Ricardo de. Explorando e construindo um conceito de gestão escolar democrática. Educação em Revista, Belo Horizonte, v. 25, n. 3, 2009, p.123-140. 
SOUZA, et al. Controle social na área da educação: um estudo das unidades escolares de ensino fundamental do município de Sertanópolis/PR. Londrina: UEL, 2017.

Grécia Gracielle da Silva Bezerra é graduada em Pedagogia pela Universidade Federal de Pernambuco.

Orcid: https://orcid.org/0000-0003-2921-3555.

Endereço postal completo: Rua Lemos Torres, 49 Bloco F/108 - Recife - PE - Brasil.

E-mail: bezerraaicerg@gmail.com

Laêda Bezerra Machado é professora na Universidade Federal de Pernambuco. Orcid: https://orcid.org/0000-0002-9524-0319.

Endereço: Rua Edson Alvares, 115/ 1302 - Recife - PE - Brasil.

E-mail: laeda01@gmail.com.

Critérios de autoria: as autoras participaram da concepção, execução, análise, interpretação e redação.

Recebido em 17 de junho de 2021.

Aceito em 29 de setembro de 2021.

(c) $($ i) $\$$ 